SHS Web of Conferences 7, 01002 (2014)

DOI: $10.1051 /$ shsconf / 20140701002

C) Owned by the authors, published by EDP Sciences, 2014

\title{
Research on Development Measures of Low-carbon Transportation in Beijing
}

\author{
Zong Gang ${ }^{1}$,Yang Lijie ${ }^{2}$,Yan $\mathrm{Hua}^{3}$ \\ ${ }^{1}$ College of Economics and Management, Beijing University of Technology, 100124 Beijing, China \\ ${ }^{2}$ Institute of Recycling Economy, Beijing University of Technology, 100124 Beijing, China \\ ${ }^{3}$ College of Architecture and Urban Planning, Beijing University of Technology, 100124 Beijing, \\ China
}

\begin{abstract}
With the development of economy, vehicle ownership is growing rapidly. People gradually concentrate on the energy consumption of transportation industry and environmental pollution. Because of air pollution, energy consumption, climate change and other problems, people in major cities pay more attention to energy conservation and emission reduction in transportation. Transportation industry is an important source of energy consumption and carbon emission. Facing the task of energy conservation and emission reduction in the Twelfth Five-year Plan for economic and social development, it is extremely urgent to adjust the transportation industry and take road of low-carbon transportation. Low-carbon transportation is an important breakthrough for Beijing to readjust industrial structure and transform the economic development pattern; it is also a demand for Culture-enriched Beijing, Technology-empowered Beijing, Environmentfriendly Beijing as well as an inevitable choice for the coordinated development of economy, society and environment. This paper analyzes the status quo and major problems facing Beijing low-carbon transportation and comes up with policy advice for low-carbon transportation development.
\end{abstract}

Keywords. low-carbon transportation; carbon emission; measures

\section{Introduction}

In November, 2009, executive meeting of the State Council formulated the target of carbon emission of 2020 in our country - compared with that of 2005, carbon dioxide emissions of GDP than in should decreased $40 \%$ to $45 \%$ per unit, and consider it as long-term planning for national economic and social development. During "Twelfth Five-Year Plan of National Economy and Twelfth Five-Year Plan of Social Development" period, the main goal of energy conservation in Beijing is - compared with that of 2010 , in 2015 , energy consumption decreased by $17 \%$, carbon dioxide emissions dropped by $18 \%$, controlling total amount of energy consumption within 90 million tons.

Beijing now is faced with severe resources and environment problem. It's urgent to carry out energy reservation and emission reduction. Carbon emission in transportation accounts for $25 \%$ of that in global, while in Beijing, the ratio is even reaching $45 \%$. Carbon emission in transportation, which excels industrial emission, has become main resource of carbon emission in Beijing. With the 
increasing of Per Capita GDP and vehicle ownership, carbon emission in transportation will still keep on increasing.

Vehicle exhaust has become the main cause which has a bad influence on air quality in Beijing. Recently, hazy weather frequently happens, which has a serious effect on people's daily life and health. According to current trend-more than 1300 vehicles increase per day in Beijing, if we don't take any steps, in 2015, average travel speed of Beijing vehicles in rush hours may below 15 kilometers per hour, and the problem of exhaust emission will become more and more severe. With the continuous and rapid development of economy in our capital, the process of urbanization, modernization and mechanization has been sped up. At the same time, the conflicts between population, resources and environment are exacerbated. The control for carbon emission in transportation is the key to construct the low-carbon Beijing, and also the breakthrough and a beginning for Beijing to be the world city.

\section{The connotation of low-carbon transportation}

Low-carbon transportation, which develops from low-carbon economy, is the concrete expression and application of low-carbon economy in transportation. Low-carbon transportation, environmentfriendly transportation, and sustainable transportation are all ideas concerning sustainable development; and there is no essential difference between them. Low-carbon economy was originally proposed by the UK government in energy blue book Our Future Energy and Resources: Establishing Low-carbon Economy in 2003, it mainly refers to a kind of sustainable economic development mode featuring low-energy, low-emission and low-pollution.

In our country, low-carbon transportation is originally proposed by scholar Su Fengming. He holds the view that low-carbon transportation is based on full awareness of the harm of climate change and energy crisis, taking resources conservation and carbon emission reduction, realizing the sustainable development of economy and living environment and realizing the harmonious development between man and nature as fundamental starting point, according to the economic characteristics of modern technology of various mode of transportation, adopting system control and creative application of environment-friendly technology to improve the efficiency of the single mode of transportation and the structure of transportation; to realize the effective control of transportation demand and management innovation in transportation organizations, and finally realize the low-carbon development of the whole industrial chain in transportation in complete period and propel the lowcarbon transition of social and economic development.

At present, we still have no concrete definition for the term "low-carbon transportation". Its essence is a kind of sustainable transportation mode featuring high energy efficiency, low pollution, low energy consumption and low emission. Combining with the development strategy of "Cultureenriched Beijing, Technology-empowered Beijing, Environment-friendly Beijing", Beijing lowcarbon transportation centers on relieving urban traffic congestion, establishing public transportation oriented city and building a new transportation system featuring "Culture-enriched transportation, Technology-empowered transportation and Environment-friendly transportation" to propel comprehensive, balanced and sustainable development of Beijing transportation.

\section{Main problems in development of low-carbon transportation of Beijing}

With the rapid development of society and economy in Beijing, the process of urbanization, modernization and mechanization continuously speeds up. At the same time, the conflicts between population, resources and environment are exacerbated. The current state of low-carbon transportation of Beijing is still severe. With the rapid increasing of population, the travel amount keeps on increasing and the demand for travel becomes more complex and diverse. At the end of the "Twelfth Five-Year Plan", the average travel amount per day in our capital will reach 54,000,000 to 59,000,000, and the average travel distance will increase to 11 kilometers. The sustained and rapid growth of vehicle ownership cannot slow down by itself, travel structure optimization and adjustment is facing 
great challenges and it's hard to increase the ratio of environment-friendly transportation. Transportation in Beijing will be confronted with the severe challenges of the sustainable and rapid growth of population and vehicle ownership.

\subsection{The rapid growth of permanent resident population in Beijing}

The population of permanent resident of Beijing in 2012 is 20,693,000, compared with the statistics $(20,186,000)$ in 2011 ; the number of population has increased 500,000 , the growing rate reaches $2.5 \%$. The population of permanent resident is $19,610,000$, compared with that of 2005 , the number of population has increased $4,230,000$, and the growing rate is $27.5 \%$ with progressive increase of $4.98 \%$ per year. The rapid increase of permanent resident in Beijing means the increase of social measure of consumption. This situation will arise more demand for transportation, energy and resources, which will increase carbon emission and impose great pressure on the fragile transportation system in Beijing.

\subsection{The growth of per capita GDP in Beijing}

As for the growth of per capita disposable income, per capita GDP of Beijing in 2000 is 2,915 dollars, while per capita GDP of Beijing in 2010 has increased to 11,218 dollars which is 3.5 times than that of 2000. As it shows in figure 1, with the rapid increasing of people's living standard, the demand for shopping, entertainment, travel, fitness and so on is correspondingly increasing. And it will also indirectly arouse the need for more complex and diverse transportation. Thus, energy consumption and carbon emission in transportation will correspondingly increase, which brings new challenges to the task of energy conservation and emission reduction.

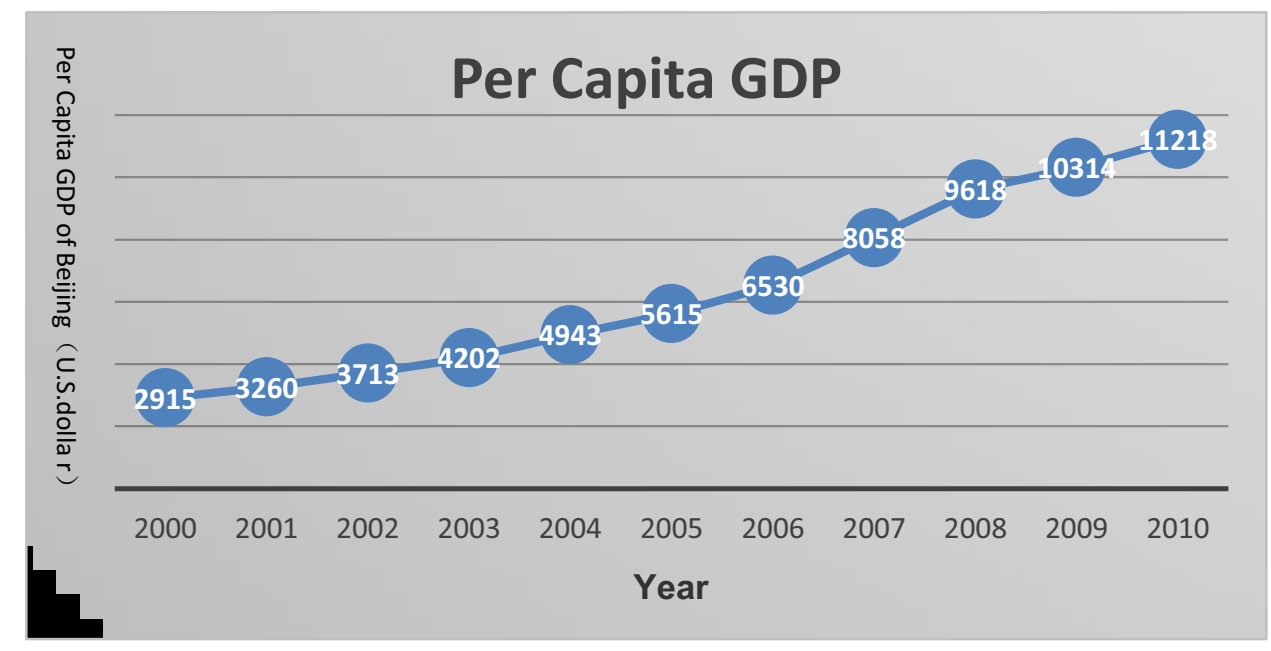

Figure 1. Per capita GDP of Beijing in ten years

\subsection{The rapid increase of vehicle ownership in Beijing}

From 2005 to 2012, the vehicle ownership in Beijing has increased 2,620,000, the growing rate even reaches $101 \%$, and the average growing rate is $12.6 \%$ per year. Meanwhile, the growth of private cars is the most rapid, which growth rate even reaches $120 \%$. In 2012 , vehicle ownership in the whole city is $5,200,000$, compared with that in 2011; the number has increased 800,000 which growth rate is $16.8 \%$. During the whole year, 67,000 vehicles are increased per month, which means the growth rate and speed of vehicle ownership has hit a new height in the history. 


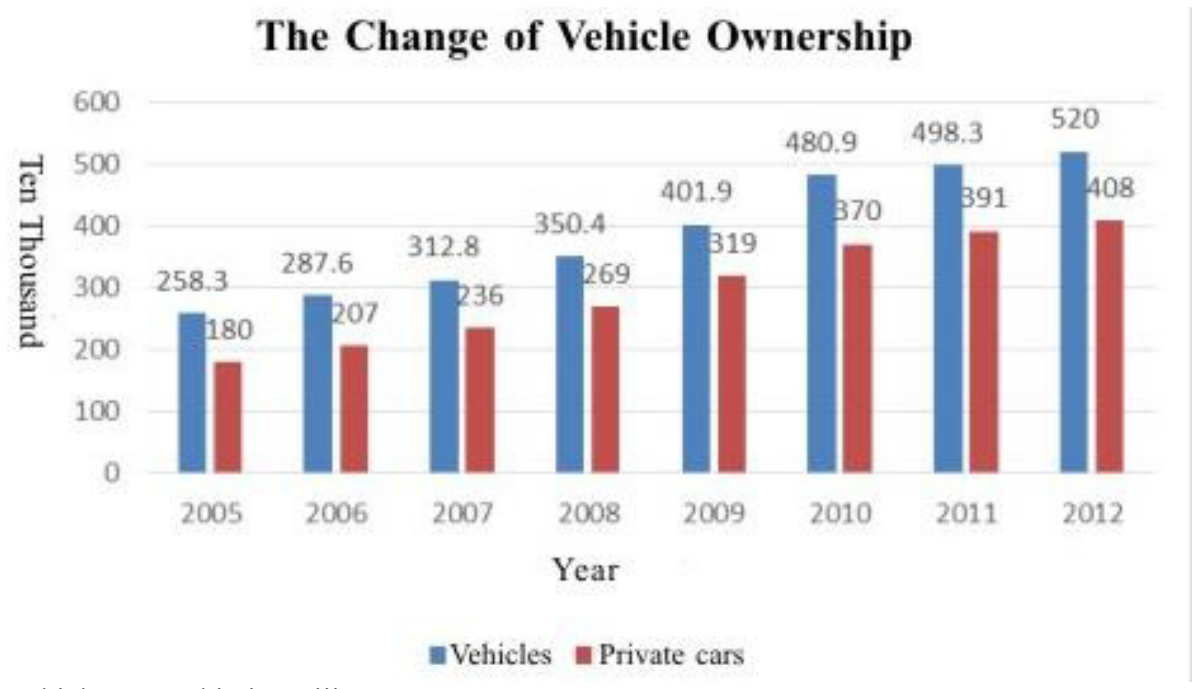

Figure 2. Vehicle ownership in Beijing

\subsection{Travel taking on public transportation accounting for a comparatively low proportion in structure of travel}

The mode of travel is an important factor which has an effect on carbon emission in transportation. As it show in figure 3, from 2006 to 2009 , travel taking on public transportation accounts for $28 \%$, which means that mass transit fails to be the leading choice of travel. Travelling by cars, which has the greatest impact on transportation carbon emission, accounts for 34\% of all the travel modes. It has been the most important mode for people's travel, and shows a trend of continuous increasing. Traveling by bicycles, which is a zero-emission travel mode, possesses fewer and fewer proportion. In 1986 , the proportion is $62.7 \%$, while it declines to $16.4 \%$ in 2010 . We can figure out in the following figure, the share ratio of public transportation is low. The change of people's travel mode has a great effect on development of low-carbon transportation in Beijing.

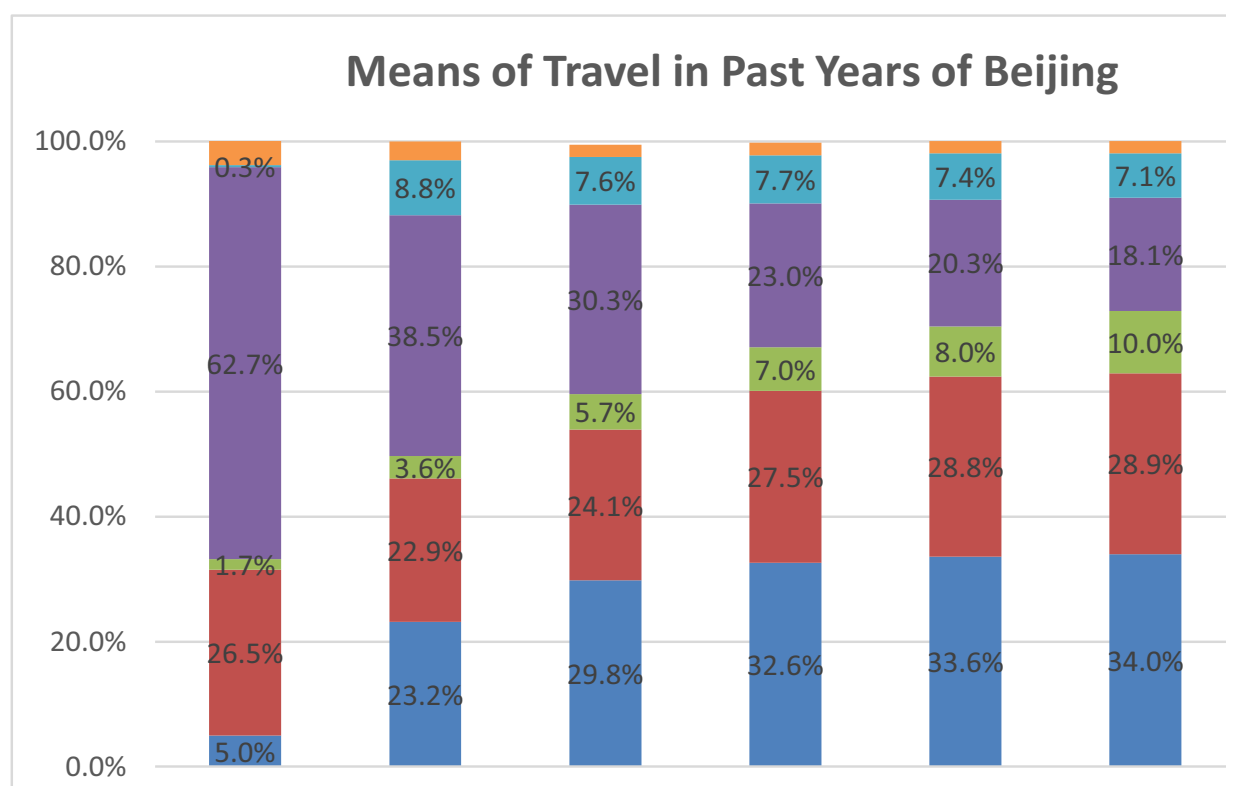

Figure 3. The share rate of various travel modes in Beijing 


\subsection{Heavy traffic jams}

In addition to the influence of travel distance, carbon emission in city is also affected by travel time and transit speed. The growth of private cars in Beijing, which has exceeded the upper limit which roads in Beijing can bear, gives rise to traffic jam and increases energy consumption. In a traffic jam, carbon emission is $15 \%$ higher than that under normal conditions. Traffic jams waste lots of resources, and the corresponding increasing transportation emission also brings Beijing with serious pollutions.

\section{Strategies for development of low-carbon transportation}

\subsection{The structured low-carbon}

\subsubsection{Controlling the scale of population by readjusting industrial structure is the fundamental strategy}

With the rapid development of economy in Beijing, permanent resident population of Beijing is jumping, as well as the growth rate of per capita GDP. This gives rise to obstacles to develop lowcarbon transportation in Beijing. However, it's necessary to meet people's needs for development and materials by economic output, and it matters a lot for social stability and development. We should not reduce emission from transportation at the cost of economic development, but through readjusting structure to realize energy conservation and emission reduction. Industrial structure in Beijing should be further readjusted. We should upgrade industries, gradually develop high-tech industry and highend service, and raise the threshold of these industries. It is important for Beijing to develop lowcarbon transportation by controlling the scale of population through readjusting structure, optimizing population structure and quality of population, and then controlling the continuous growth of transportation demands.

The rapid growth of population scale in Beijing has exceeded the limit of ecological system. Therefore, Beijing should center on service, function orientation, population control, and then raise the demands for low end industries, figure out a list of industries which are negative to Beijing's development and then forbid them enter Beijing's market. At the same time, government should improve, control and standardize these barbershops, salvage stations, basements, makeshift houses and group-oriented leasing houses. That is, Beijing should control population through market.

\subsubsection{Further deepening and giving priority to the development of public transportation}

Accelerate construction of central city rail transit, and improve density of city center line. New public transit lines which are opened during "Twelfth Five-year Plan", account for $80 \%$ of all lines. Departure interval is 2 to 2.5 minutes. We should improve safe operation service facilities of rail transit lines and raise the carrying capacity of existing facilities. We should build rapid transit commuting network, and improve the efficiency of commuter travel. We should focus on the center of the city, rely on the rail transportation, urban freeway network, bus lanes, large capacity rapid transit bus lines and conventional bus lines, improve the comprehensive passenger transport junction, centers of ground public transportation and three-level transfer system, and build rapid transit commuting network. We should further optimize and adjust public transit network, and improve public transit accessibility. We should increase district and regional extension line and "Pocket Line", perfect convergence between rail transit and bus transportation which may make sure convenient travel. We should accelerate the construction of comprehensive transportation junction and bus station, which can provide convenience for citizens to transfer. We should also improve public transportation transfer facilities which have large volume of passenger flow. We should also construct Park and Ride $(\mathrm{P}+\mathrm{R})$ parking lot to encourage citizens to take public transportation.

\subsection{Technical low-carbon}




\subsubsection{Developing intelligent transportation system}

We should make full use of new information technology such as IOT, cloud computing and so on, efficiently get advanced information technology, data communication transmission technology, electron sensor technology, control technology and computer technology together, and apply them to the whole ground transportation management system. We should build a comprehensive transportation management system which is more accurate, and efficient, and can play a role in wide-range and on all sides. We should strive to develop ITS which can provide more detailed and reliable information service for public travel, at the same time; improve the operating efficiency o public transportation and service quality to further improve the ratio of public transit. ITS can also real time monitor and control vehicles on the roads to maximum extent, and resolve problems such as car no-load, lowspeed travel and traffic jams to further reduce carbon emission in transportation which is caused by these problems. This is a positive signal for development of low-carbon transportation.

\subsubsection{Accelerating technology research and development of low-carbon transportation and assist the development of low-carbon development}

The energy intensity of transportation obviously has a negative effect on transportation carbon emission. Under the circumstances which energy consumption continuously grows quickly and readjustment of industrial structure faces difficulties, it is the most important way to quicken energy conservation and emission reduction by improving efficiency of energy utilization. The improvement of energy utilization efficiency depends on advance of technology. We can increase investment on advanced energy-saving technology, propel exploitation, transformation and utilization of new energies by developing and popularizing innovative technology, and at the same time strengthen researches on energy-efficient cars and construct environment-friendly transportation system to reduce carbon emission.

We should strengthen innovations on technologies of low-carbon transportation, improve and upgrade used means of transportation and increase the ratio of new energy applying to transportation energy. We should carry on technology innovations and promotion in various fields, such as urban traffic planning design, transportation facilities construction and maintenance, comprehensive transportation system and safety, energy-saving and new energy vehicles, public transit management, to reduce fossil energy consumption in transportation and carbon emission.

\subsubsection{Strengthen international low-carbon technology communication and cooperation}

For some developed countries have made some breakthroughs in development of low-carbon energy technology and low-carbon transportation, such as EU, Japan, Germany, and America, they have rich experience on development of low-carbon transportation. On one hand, we should strengthen international technology cooperation and communication, bring in and absorb advanced technologies and experience from these countries to propel development of resources and low-carbon transportation in our country; on the other hand, we should explore methods which is fit for development of lowcarbon transportation in Beijing based on the reality and current state of transportation in Beijing.

\subsection{Political low-carbon}

\subsubsection{Making use of administrative economy to continuously manage demands of transportation}

We should formulate relative economic policies and propel development of low-carbon transportation by economic methods. We should actively mirror advanced experience from other countries, formulate relative policies which are fit for current state of Beijing, and continuously implement existing transportation policies. We can control volume of vehicle flow by increasing vehicle use 
taxes and private cars parking cost and fuel oil taxes and reduce needs for vehicles. Combining with other strategies, volume of traffic in rush hours has reduced $45 \%$, the number of public transportation has increased $50 \%$. At the same time, promote the use ratio of public transportation by subsidy for public transportation.

Control the growth of minibus ownership and reduce the rapid growth of vehicle ownership. We can freely allocate index of minibuses for enterprises, social organizations and individuals who are eligible by lottery, based on principles of fair, open, justice and free. We should adjust the growth rate of minibus in enterprises and individuals to restrain the rapid growth of minibus.

Continue to implement and improve traffic restriction measures in the region in rush hours. Continue to implement restrictions of vehicles on weekday in rush hours, strengthen management of cars which from other towns, and effectively reduce volume of transportation in rush hours in central city. We should reduce volume of transportation in central city, and vehicle owners should bear a reasonable cost. We should adjust parking fees, strengthen parking order and management. The parking fees depend on religion and implement tiered pricing based on "center above the periphery, in the road above outside road, on the ground above underground". We should strengthen the management of parking space, remediate parking order, and increase penalties for illegal road parking.

\subsubsection{Strengthen advocation and arouse the public's awareness of low-carbon travel}

We should arouse citizens' enthusiasm for construction of low-carbon transportation. We should advocate citizens to travel environment-friendly. We should make full use of media, such as newspapers, broadcast, TV and network, and public service advertising to advertise environmentfriendly travel and environmental protection knowledge. We can advocate adoption of public transportation, bicycle riding or shopping online by carry out "Public Transportation Week", "No Car Day" and other activities. We should promote citizens' awareness of modern transportation, lead the transformation of consumption patterns of transportation, and advocate green travel such as travelling by public transportation means, riding bicycles or on feet.

\section{Conclusion}

With the process of urbanization and rapid development of economy, the level of mechanization in Beijing is more and more high. Resources and environment in Beijing are now facing great challenges. In development of Beijing, it becomes more and more important to conserve energy and reduce emission in transportation by readjusting industrial structure and developing low-carbon technology. It's a starting point as well as a breakthrough to solve the conflicts between population, resources and environment by encouraging environment-friendly travel and developing low-carbon transportation.

\section{Acknowledgement}

I'd like to express my acknowledgement for support of key discipline project of Beijing "Resources, Environment and Circular Economy". (GN: 033000541213004)

\section{References}

1. Su Fengming. The Definition of Low-Carbon Transportation and Ways of Realization[J]. Comprehensive Transportation, 2010(5).

2. Hou Gang, Li Bing. Researches on Low-Carbon Transportation in City[J]. Ecological Environment, 2011(7).

3. Wei Lan, Bao Lulin. The Current State, Problems and Policy Strategies of Development of Lowcarbon Transportation in Beijing[J]. Highway, 2011(5). 
4. Su Taoyong, Zhang Huijian. Empirical Research on Influence Factors of Urban Transportation Carbon Emission[J]. Industrial Engineering Management, 2011(5).

5. Chen Fei, Chu Dajian. Development Mode, Current Problems and Targeted Strategies of Urban Low-Carbon Transportation[J]. Urban Planning Forum, 2009(6).

6. Sun Dehong. Development Mode and Strategies of Urban Low-Carbon Transportation[J]. Environment Protection in Transportation, 2011(1).

7. Liu Wenyu. Analysis on Prospect of Low-Carbon Transportation in Beijing[J]. Comprehensive Transportation, 2010(9). 